No further cases of rubella occurred, and there was no clinical or serological evidence that any women in early pregnancy under our care at the time of the epidemic contracted the disease.

Immune globulin was not given to susceptible personnel for fear of masking the continuation of the epidemic, but rubella vaccine was offered and was given. The side effects of the vaccine-rash, mild arthralgia, or constitutional disturbance-were not stressed, but female recipients were advised to take positive steps to avoid pregnancy in the six weeks after vaccination.

Although the percentage of susceptible people was lower than previously recorded in both patients and staff, the difference was not statistically significant when compared with the results of previous studies in the same hospital. The danger that nurses and doctors susceptible to rubella may pose to patients in early pregnancy in the course of an epidemic was made apparent to us by this episode. Contact in antenatal clinics is very close and could have disastrous consequences for the fetus if the medical attendant is incubating rubella and is infectious. It has been our policy to protect susceptible nurses working in our unit by offering Cendehill vaccine. It seems advisable that the immune status of doctors, nurses, or other attendants who may come into close contact with patients in early pregnancy, should be ascertained serologically, and that seronegative persons should be encouraged to accept vaccination in the interests of the patients. Such will be our policy henceforth.

We are grateful to J. Bebbington, who performed the serological tests.

\section{References}

Beazley, J. M., Hurley, Rosalinde, Middlebrook, Celia, and Rumpus, M. F. (1971). British fournal of Preventive and Social Medicine, 25, 140.

Dudgeon, J. A. (1967). In Modern Trends in Medical Virology, ed. R. B. Heath and A P. W aterson, P. 111 .

Dudgeon, J. A., Marshall, W. C., Peckham, Catherine S., and Hawkins, G. T. (1969a). British Medical' Fournal, 1, 271.

Dudgeon, J. A., Marshall, W. C., and Peckham, Catherine S. (1969b). American fournal of Diseases of Childhood, 118, 237.

Green, R. H., Balsamo, M. R., Giles, J. P., Krugman, S., and Mirick, G. S. (1964). Transactions of the Association of American Physicians, 77, 118. Public Health Laboratory Working Service Party on Rubella (1970). British Medical Fournal, 2, 497.

Sever, J. L., Brody, J. A., Schiff, G. M., McAlister, R., and Cutting, R. (1963). Fournal of the American Medical Association, 191, 624.

\title{
Effect of Metoclopramide on Gastric Emptying during Labour
}

\author{
F. A. HOWARD, D. S. SHARP
}

British Medical fournal, 1973, 1, 446-448

\begin{abstract}
Summary
The effect of a single dose of metoclopramide (Maxolon) on the gastric emptying rate of a liquid test meal was measured in a group of parturient women by a doublesampling dye-dilution technique. The subjects were given either metoclopramide $10 \mathrm{mg}$ or sterile water by intramuscular injection on a double-blind random basis at the start of the test. The gastric emptying rate was significantly increased in those women who had received the metoclopramide as compared with those who had received the placebo.
\end{abstract}

\section{Introduction}

Mendelson (1946) first reported the development of acute pulmonary oedema after the inhalation of vomitus in women in labour undergoing emergency general anaesthesia. Since then successive reports on maternal mortality have drawn attention to this syndrome. In the Confidential Enquiries into Maternal Deaths in England and Wales covering the years 1967-9 (Department of Health and Social Security, 1972) a total of 451 maternal deaths were considered. Of these, 50 were associated with general anaesthesia and at least half of these were caused by the inhalation of regurgitated gastric contents. These figures were

Department of Obstetrics and Gynaecology, University Hospital of South Manchester, Manchester M20 8LR

F. A. HOWARD, M.B., M.R.C.o.G., Senior Registrar

D. S. SHARP, M.B., M.R.C.o.G., Registrar remarkably and disappointingly similar to those contained in the previous two triennial reports on maternal mortality.

Obstetricians have long been aware of the hazard constituted by vomiting associated with emergency general anaesthesia in women during labour. In such patients the vomitus may contain the remnants of food ingested many hours previously, and it is largely as a result of such clinical experience that it has been thought that the gastric emptying rate is substantially decreased in these women. Such studies that have been reported support this belief. Hansen (1937) attempted to measure the gastric emptying rate by administering a fluid test meal containing methylene blue and then aspirating samples from the stomach until such time as there was no further trace of the dye in the aspirate. In this way he showed that the gastric emptying time of pregnant women was about double that of non-pregnant women. Davison et al. (1970) compared the gastric emptying times for a fluid test meal in normal, non-pregnant women and women in late pregnancy. While calculations of the half life of gastric emptying showed no significant difference between the two groups the volumes of fluid remaining in the stomach after 30 minutes were significantly greater in the pregnancy group.

Metoclopramide is a chlorbenzamide derivative which uas been shown to inhibit vomiting induced centrally by apomorphine (Laville and Margarit, 1964) and to accelerate gastric emptying by a direct effect on the autonomic nuclei (Jacobie and Brodie, 1967). Eisner (1968) showed by in-vitro studies that metoclopramide sensitizes gastric smooth muscle fibres to the effect of acetylcholine, thus potentiating the effect of the latter. There are many reports of the antiemetic properties of metoclopramide. Clark and Storrs (1969) showed a reduced incidence of postoperative vomiting in patients treated with metoclopramide, and Johnson (1971) demonstrated its value in the management of flatulent dyspepsia. Several workers have reported favourably on its use in treating vomiting associated with early pregnancy, 
and McGarry (1971) showed that it is effective in reducing the incidence of vomiting during the first stage of labour. JustinBesançon et al. (1964) showed by a fluoroscopic technique that the intravenous injection of metoclopramide stimulated gastric peristalsis in man, a finding which was supported by Margieson et al. (1966), who showed that it accelerated the emptying of barium meal from the stomach and its passage to the caecum. This is the rationale for the widespread use of metoclopramide in radiodiagnostic studies of the gastrointestinal tract. It can therefore be said that metoclopramide is an effective modifier of gastric motility.

The present investigation was undertaken to determine whether metoclopramide would modify the impaired gastric function which is responsible for delayed gastric emptying in women during labour. In itself delayed gastric emptying is considered to be an important factor in the aetiology of Mendelson's syndrome. The approval of the hospital ethical committee was obtained before starting the investigation.

\section{Patients and Methods}

All 30 patients in the trial were primigravidae who had volunteered during the antenatal period and were allocated by a double-blind, randomized procedure to receive either metoclopramide $10 \mathrm{mg}$ or a placebo (sterile water) by intramuscular injection after the ingestion of a $750-\mathrm{ml}$ fluid test meal. No patient was included who gave a history of heartburn or dyspepsia, since it was shown by Davison et al. (1970) that there is a greater impairment of gastric motility in such women. Further work is planned to study this group.

The trial was initiated in each case once labour had definitely become established and the cervix had dilated to at least $2-3 \mathrm{~cm}$. In no case had labour been established for more than four hours. The fetal presentation was cephalic in each case. Following the hospital policy of active management of labour all of the patients were at least at term and had had labour induced by forewater amniotomy followed by intravenous oxytocin (Syntocinon) infusion. Pethidine $150 \mathrm{mg}$ was given as required by intramuscular injection to provide adequate analgesia. Extrapyramidal signs of the dystonic type have been reported to occur after the concurrent administration of metoclopramide and drugs of the phenothiazine group (P. J. Roylance, personal communication), and for this reason promazine (Sparine) was not given to any of the patients. This was the only departure from the normal hospital routine for the management of women during labour. None of the patients had had any solid food for at least 18 hours before the start of the investigation.

A nasogastric tube (F.G. 12) was passed and the gastric contents were aspirated. The gastric emptying rate was measured by the double-sampling technique described by George (1968). A test meal of $750 \mathrm{ml}$ of water at $37^{\circ} \mathrm{C}$ containing phenol red $(30 \mu \mathrm{g} / \mathrm{ml})$ as a marker was run from a drip-feed bottle through the nasogastric tube into the patient's stomach. This method was chosen in preference to the patient drinking the fluid, since less nausea was induced and it was possible in this way to standardize the administration of the test meal. A minimum time of 10 minutes appeared to be critical for the infusion, since any attempt to infuse at a faster rate resulted in nausea and vomiting. Zero time was taken as the moment when the last of the test meal passed down the nasogastric tube, and it was at this time that the injection of either metoclopramide or placebo was given.

Paired samples of the gastric contents were withdrawn at 10minute intervals immediately before and after an accurately measured volume of a standard solution of phenol red $(450 \mu \mathrm{g} /$ $\mathrm{ml}$ ) had been added to the stomach contents. The volume added was initially $2 \mathrm{ml}$, but this was progressively reduced to $0.5 \mathrm{ml}$ as the volume of the stomach contents appeared to diminish. To facilitate thorough mixing of the phenol red solution with the gastric contents and so improve the sampling accuracy, vigorous aspiration and reinfusion of the stomach contents was performed 10 times using a $20-\mathrm{ml}$ syringe to its full capacity. Previous investigation had shown that this technique produced uniform mixing of the fluid gastric contents. The sampling was continued for at least two hours but in no case for longer than three hours. During this time the patients were asked to remain lying in the supine position with their heads supported by two pillows. Inevitably some movement occurred during uterine contractions but an attempt was made to standardize the posture of all the patients during the sampling. In each case the residual gastric contents were aspirated at the conclusion of the investigation.

The concentration of the phenol red in each gastric sample was measured by a modification of the method of Hunt (1954) as described by Davison et al. (1970). The volume (V) of the gastric contents was calculated for each sample using the formula $\mathrm{V}=\mathrm{v}\left(\mathrm{C}-\mathrm{C}_{2}\right) \div\left(\mathrm{C}_{2}-\mathrm{C}_{1}\right)$, where $\mathrm{v}$ equals the volume of the standard solution added to the stomach, $C$ equals the concentration of the standard solution, $\mathrm{C}_{1}$ equals the concentration of dye in the first of the paired samples, and $\mathrm{C}_{2}$ equals the concentration of dye in the second of the paired samples.

\section{Results}

Five patients were unable to tolerate the nasogastric tube during labour or vomited after the administration of the test meal and were therefore withdrawn from the trial, thus reducing the number of participants to 25 . Of these, 13 were subsequently found to have received metoclopramide $10 \mathrm{mg}$ and 12 to have received the placebo.

Metoclopramide had no detectable adverse effects on the patients, the fetuses, or the progress of labour. The character and frequency of the uterine contractions were similar in each group and the mean duration of labour in the two groups was not significantly different $(P>0.3)$. All the patients had spontaneous vaginal deliveries. The Apgar scores of all the babies at one and five minutes were greater than 7 and the clinical condition gave no cause for alarm in any of them. At no time were any extrapyramidal effects observed. These findings therefore support those of McGarry (1971), who found that metoclopramide had no adverse effects when administered to women during labour.

The mean volumes remaining in the stomach at each sampling time are shown in the table and are plotted graphically in fig. 1.

Mean Volumes ( \pm S.D.) of a 750-ml Fluid Test Meal remaining in the Stomach at the Times indicated in Patients who had received either Metoclopramide or Placebo

\begin{tabular}{|c|c|c|c|c|c|c|c|c|c|c|c|c|c|}
\hline \multicolumn{2}{|c|}{ Time in min.: } & 10 & 20 & $3 c$ & $4^{r}$ & 50 & 60 & 70 & 80 & 90 & 100 & 110 & 120 \\
\hline & & $\begin{array}{l}87 \\
33\end{array}$ & $\begin{array}{l}451 \\
150\end{array}$ & $\begin{array}{l}363 \\
119\end{array}$ & $\begin{array}{l}293 \\
134\end{array}$ & $\begin{array}{r}278 \\
142\end{array}$ & $\begin{array}{l}240 \\
111\end{array}$ & \begin{tabular}{|l|}
207 \\
107
\end{tabular} & $\begin{array}{l}187 \\
106\end{array}$ & $\begin{array}{r}161 \\
94\end{array}$ & $\begin{array}{r}146 \\
81\end{array}$ & $\begin{array}{r}126 \\
74\end{array}$ & $\begin{array}{r}105 \\
45\end{array}$ \\
\hline Control & $\left\{\begin{array}{l}\text { Mean } \\
\text { S.D. }\end{array}\right.$ & $\begin{array}{r}652 \\
69\end{array}$ & $\begin{array}{r}613 \\
41\end{array}$ & $\begin{array}{r}567 \\
42\end{array}$ & $\begin{array}{r}538 \\
60\end{array}$ & $\begin{array}{r}511 \\
65\end{array}$ & $\begin{array}{r}488 \\
55\end{array}$ & $\begin{array}{r}463 \\
78\end{array}$ & $\begin{array}{r}468 \\
71\end{array}$ & $\begin{array}{r}417 \\
68\end{array}$ & $\begin{array}{r}401 \\
86\end{array}$ & $\begin{array}{r}386 \\
83\end{array}$ & $\begin{array}{r}362 \\
76\end{array}$ \\
\hline
\end{tabular}

Student's $t$ test was applied to these results, and this showed that there was no significant difference between the two groups in the volumes remaining in the stomach at 10 minutes $(P>0 \cdot 1)$. At 20 minutes, however, the difference became highly significant $(P<0.005)$, and from 30 minutes onwards the difference was even more significant $(P<0.0005)$. It can thus be seen that the gastric emptying rate was significantly faster after 20 minutes in patients who had received the metoclopramide than in those who had received the placebo. The regression equations for log mean volume against linear time were calculated by the method of least squares, and the results indicate a significant exponential relationship (fig. 2). From the regression lines the half life of gastric embtying was calculated. This is defined as the time taken for the volume of the stomach contents to fall by one half once an exponential relationship has been established. For the placebo group the half life was 141 minutes and for the metoclopramide group it was 51 minutes. This compares with 


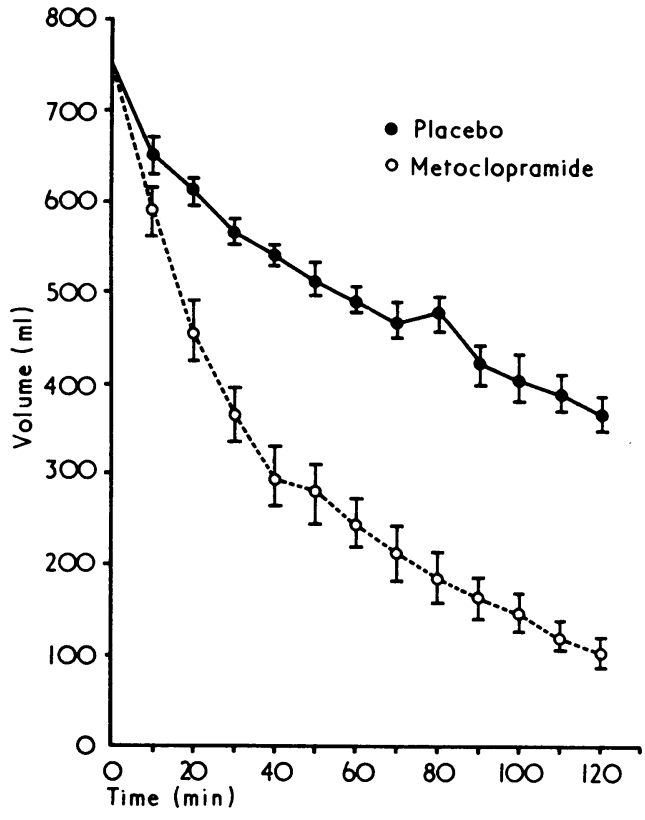

FIG. 1-Mean volumes of $750-\mathrm{ml}$ fluid test meal remaining in stomach at times indicated in patients who had received either metoclopramide or placebo. Bars represent one standard error of the mean for each group.

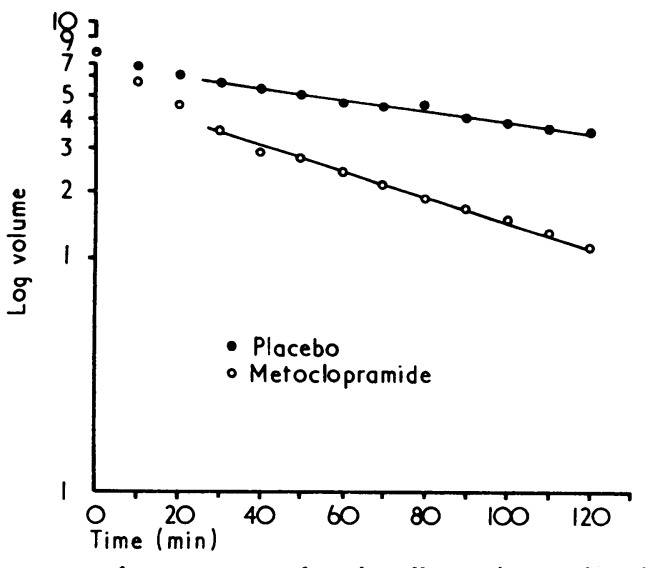

FIG. 2-Log mean volumes expressed against linear time scale using same data as in fig. 1. An exponential relationship is clearly shown, from which the half life can be calculated for each group.

a figure of 11.2 minutes for non-pregnant women obtained by Davison et al. (1970) using the same technique.

\section{Discussion}

Reference has already been made to the fact that it was not possible to infuse the test meal in less than 10 minutes without inducing nausea and vomiting. This in itself is probably indicative of impaired gastric function, since non-pregnant women are easily able to consume $750 \mathrm{ml}$ of water without experiencing nausea. The hazard which this constitutes in relation to Mendelson's syndrome is not a remote one; in the University Hospital of South Manchester about $10 \%$ of all the patients who are delivered require a general anaesthetic at some stage of their labour, and this is probably typical of most maternity units in the country. It bears repeating that during the years 1967-9, 25 women died as a consequence of vomiting associated with emergency general anaesthesia during labour. This is a hazard to which much attention has been directed in recent years, and various suggestions have been made in an attempt to reduce this alarmingly high figure. While it would be a theoretical advantage for the stomach to be completely empty during labour this is not possible in practice. The suggestion by Holmes (1956) and White (1959) that apomorphine should be administered to induce vomiting before emergency general anaesthesia would be totally unacceptable to most patients. A policy of fasting women during labour is widely practised, but this often requires intravenous medication to overcome the resulting metabolic disturbances which would otherwise have an adverse effect on the fetus and the progress of labour. Anaesthetic technique is clearly of importance, and much emphasis has been placed on the advantage of having the services of an experienced anaesthetist readily available to all maternity units.

Goldstein and Boyle (1965) suggested that impaired gastric emptying existed if more than $400 \mathrm{ml}$ of a $750-\mathrm{ml}$ test meal remained within the stomach 30 minutes after its ingestion. In this series the mean volume of the gastric contents at 30 minutes was $362.9 \mathrm{ml}$ for the metoclopramide group and $567 \mathrm{ml}$ for the control group. The half life for the two groups was 51 and 141 minutes respectively. By both of these methods of analysis of the results metoclopramide has significantly increased the gastric emptying rate.

It is probable that metoclopramide is most effective in modifying gastric motor function when this is already impaired by other factors, of which one is labour. We believe that any means of improving gastric emptying in parturient women would reduce the risk of vomiting during emergency general anaesthesia, thereby reducing the death rate due to Mendelson's syndrome. The routine administration of metoclopramide before emergency anaesthesia may help towards this goal.

We wish to extend our thanks to Dr. R. W. Burslem, at whose suggestion this work was undertaken; to Mr. D. J. Cowley for his advice; and to the patients who volunteered for the trial. The metoclopramide was kindly provided by Dr. P. J. Roylance, of Beecham Pharmaceutical Division.

\section{References}

Clark, M. M., and Storrs, J. A. (1969). British fournal of Anaesthesia, 41, 676.

Department of Health and Social Security (1972). Confidential Enquiries into Maternal Deaths in England and Wales, 1967-69. London, H.M.S.O.

Davison, J. S., Davison, M. C., and Hay, D. M. (1970). Fournal of Obstetrics and Gynaecology of the British Commonwealth, 77, 37

Eisner, M. (1968). British Medical fournal, 4, 679.

George, J. D. (1968). Gut, 9, 237

Goldstein, H., and Boyle, J. D. (1965). Gastroenterology, 49, 375.

Goldstein, H., and Boyle, J. D. (1965). Gastroenterology, 49, Holmes, J. M. (1956). Fournal of Obstetrics and Gynaecology of the British

Hunt, J. N. (1954). Guy's Hospital Reports, 103, 161.

Jacobie, H. I., and Brodie, D. A. (1967). Gastroenterology, 52, 676

Johnson, A. G. (1971). British Medical fournal, 2, 25.

Justin-Besancon, L., Laville, C., and Thominet, M. (1964). Comptes Rendus Hebdomadaires des Séarces de l'Académie des Sciences, 258, 4384.

Laville, C., and Margarit, J. (1964). Pathologie et Biologie, 12, 726.

Margieson, G. R., Sorby, W. A., and Williams, H. B. L. (1966). Medical fournal of Australia, 2, 1271 .

McGarry, J. M. (1971). British fournal of Anaesthesia, 43, 613 Mendelson, C. L. (1946). American Fournal of Obstetrics and Gynecology, 52,

White, R. T. (1959). Obstetrics and Gynecology, 14, 111. 